\section{Avaliação dos conhecimentos de equipes do Programa de Saúde da Família sobre o manejo do aleitamento materno em um município da região metropolitana de São Paulo}

\section{Knowledge assessment of Family Health Program teams on breast feeding in a Municipality of São Paulo's Metropolitan Region}

Rita de Cássia Veríssimo Ciconi 1

Sonia Isoyama Venancio 2

Maria Mercedes L. Escuder 3

1,2 Núcleo de Investigação em Saúde da Mulher e da Criança Instituto de Saúde. Secretaria do Estado da Saúde. Rua Santo Antonio, 590, $2^{\circ}$ andar. São Paulo, SP, Brasil. CEP 01.314-000. E-mail: rciconi@bol.com.br

3 Núcleo de Investigação e Estudos em Epidemiologia. Instituto de Saúde. Secretaria de Estado da Saúde. São Paulo, SP, Brasil.

\begin{abstract}
Objectives: to assess knowledge and training of Family Health Program (FHP) teams in encouraging breast feeding (BF) in the Municipality of Francisco Morato, São Paulo.

Methods: a questionnaire with questions on the profile of professionals, awareness of the need to encourage, knowledge on BF management, and training in $B F$ and organization of actions aiming at breast feeding encouragement was applied to 61 professionals of the Family Health Program in the municipality selected through random stratified sampling

Results: $45.9 \%$ of the respondents mentioned BF as one of the priority actions developed focusing on child health, $98.4 \%$ agreed to the value and advantages of BF for both mother and child, $96.7 \%$ recommended exclusive breast feeding up to six months of life, $24.6 \%$ instructed mothers to continue breast feeding up to two years old; $88.5 \%$ instruct on breast feeding position and nursing, $38.9 \%$ offer correct instructions for manual milking, $21.4 \%$ offer adequate instructions.

Conclusions: respondents are aware of the value of breast feeding and have theoretical knowledge on the subject but have difficulties to resolve practical questions concerning breast feeding management which could have a negative impact on the work developed to support nursing mothers.
\end{abstract}

Key words Family Health Program, Breast feeding, Interservice training

\section{Resumo}

Objetivos: avaliar os conhecimentos e a capacitação de equipes do Programa de Saúde da Família $(P S F)$ para o desenvolvimento de ações de incentivo ao aleitamento materno (AM) no município de Francisco Morato, São Paulo.

Métodos: um questionário contendo questões sobre características dos profissionais, sensibilização para o trabalho de incentivo à amamentação, conhecimentos sobre manejo do AM, capacitação em AM e organização das ações de incentivo à amamentação foi aplicado a 61 profissionais do PSF do município, selecionados por amostragem aleatória estratificada.

Resultados: $45,9 \%$ dos entrevistados citaram o AM como uma das ações prioritárias desenvolvidas para saúde da criança; 98,4\% reconheceram a importância e as vantagens do AM para a dupla mãebebê; $96,7 \%$ recomendam o AM exclusivo até seis meses de vida; $24,6 \%$ orientam as mães a continuarem o AM até os dois anos; $88,5 \%$ orientam sobre pega e posicionamento da mamada, sendo que $38,9 \%$ fazem a orientação de forma satisfatória; quanto à ordenha manual, $21,4 \%$ orientam satisfatoriamente.

Conclusões: os entrevistados estão sensibilizados quanto à importância do AM e têm conhecimentos teóricos sobre o tema, mas apresentam dificuldades para a resolução de questões práticas sobre o manejo da amamentação, o que pode interferir de forma negativa no trabalho desenvolvido de apoio às mães lactantes. Palavras-chave Programa de Saúde da Família, Aleitamento Materno, Capacitação em serviço 


\section{Introdução}

A Constituição Federal de 1988, no artigo 196, afirma: "A saúde é direito de todos e dever do Estado, garantido mediante políticas sociais e econômicas que visem à redução do risco de doenças e de outros agravos e ao acesso universal e igualitário às ações e serviços para sua promoção, proteção e recuperação." (1988: 112). 1

Essa Constituição constrói o Sistema Único de Saúde (SUS) - que se norteia pelos princípios éticos da universalidade, integralidade, eqüidade - e pelos princípios organizacionais da descentralização, hierarquização e participação popular.

A partir de 1990 o Sistema Único de Saúde passou a ser regulamentado pela Lei Orgânica 8080/90: "Essa lei regula em todo o território nacional as ações e serviços de saúde, executados isolada ou conjuntamente, em caráter permanente ou eventual, por pessoas naturais ou jurídicas de direito público ou privado"(1990: 18055).2

No início dos anos 90, com a municipalização, ocorreu um avanço no processo de consolidação do SUS, mas ainda com a necessidade de mudanças na forma como o sistema está organizado.

Segundo Costa Neto (2000: 46)3 "O modelo assistencial predominante no Brasil nos últimos anos caracterizou-se pela prática médica quase que exclusivamente biológica, individualista e hospitalar, apresentando baixa cobertura com elevado custo, apesar de sua eficiência técnica nas respostas pontuais de procedimentos curativos individuais, em especial nos casos complexos e de realização hospitalar ".

Essa necessidade de mudanças nas práticas de atendimento fez com que outros programas fossem criados, dentre eles o Programa de Agentes Comunitários de Saúde (PACS) em 1991 e o Programa de Saúde da Família (PSF) em 1994.

O PSF foi criado em 1994, pelo Ministério da Saúde, em virtude do êxito do PACS, especialmente nas regiões Norte e Nordeste, quando os secretários municipais de saúde queriam apoio financeiro para efetuar mudanças na forma operacional da rede básica de saúde, expandindo o PACS para outros níveis de profissionais.

O PSF pretende integrar os princípios do SUS com a comunidade, trabalha com uma concepção de saúde centrada na promoção da qualidade de vida, tem uma relação mais próxima entre as pessoas, tende a humanizar a assistência estabelecendo uma nova relação entre os profissionais da saúde e a comunidade. 4

O programa é tido como incremental do SUS com um conjunto de modificações no desenho operacional de políticas públicas, devendo ser uma decisão política do gestor consolidado com a comunidade.

As bases do programa destacam que, ao contrário do modelo tradicional, centrado na doença e no hospital, o PSF prioriza as ações de proteção e promoção à saúde dos indivíduos e da família, tanto adultos quanto crianças, sadios ou doentes, de forma integral e contínua. 5

As equipes do Programa de Saúde da Família são formadas por um médico generalista, uma enfermeira, um auxiliar de enfermagem e quatro a seis agentes comunitários. Cada equipe deve assistir de 600 a 1000 famílias, com limite máximo de 4500 habitantes, sendo que cada agente comunitário cobre uma área aproximadamente de 20 a 250 famílias. Essas definições dependem das realidades geográficas, econômicas e sócio-políticas da área, levandose sempre em conta a densidade populacional e a facilidade de acesso à unidade. $\mathrm{O}$ agente comunitário passa a ser o vínculo mais forte entre a equipe e a comunidade, pois sua função está ligada à divulgação e aplicação das atividades propostas por toda a equipe, através das visitas domiciliares. $\mathrm{O}$ vínculo é uma conquista, não um acontecimento imediato. Quanto mais apropriado for o vínculo, melhor será o resultado. 4

$\mathrm{O}$ trabalho das equipes do PSF prioriza a assistência a alguns grupos populacionais considerados de maior risco a agravos: crianças menores de dois anos, gestantes, portadores de hipertensão, diabetes, tuberculose e hanseníase. Dentre as ações desenvolvidas pelas equipes de saúde se destaca a assistência materno-infantil, que envolve a promoção e o manejo do aleitamento materno (AM).

Múltiplas pesquisas científicas comprovam que o leite materno exclusivo até seis meses de vida e complementado até os dois anos ou mais é fundamental para combater a desnutrição precoce, reduzir a morbidade e a mortalidade infantil.6-8

Com base em evidências cientificas, que apontam inúmeras vantagens dessa prática para mães e bebês, a promoção do aleitamento materno tem sido colocada como uma prioridade no contexto das políticas voltadas à saúde materno-infantil.

No Brasil, mediante os esforços e a elaboração de um conjunto de atividades desenvolvidas pelo Ministério da Saúde desde 1981, a prática da amamentação tem se recuperado.

Segundo Venancio e Monteiro 9 a duração mediana da amamentação no país passou de 2,5, em 1975, para 5,5 meses em 1989. Verifica-se principalmente esse aumento em áreas urbanas, na região Centro-Sul do País, entre mulheres de maior renda e maior 
escolaridade. Os resultados da Pesquisa Nacional sobre Demografia e Saúde (PNDS), realizada em 1996, confirmam a tendência de aumento da duração mediana da amamentação, estimada em torno de sete meses. 10 Pesquisa realizada pelo Ministério da Saúde nas capitais brasileiras, em 1999, aponta uma duração mediana de amamentação de 9,9 meses.

Comparando-se os dados de aleitamento materno exclusivo em menores de quatro meses, observa-se um aumento importante dessa prática no país, passando de uma frequiência de 3,6\% em 1986 para $35,6 \%$ nas capitais estudadas. ${ }^{11}$

Através desses estudos pode-se verificar que a situação nacional do aleitamento materno está em ascensão, porém longe de atingir as metas da Cúpula Mundial pela Infância. 12 Dessa forma, o aleitamento materno tem muito a ser desemvolvido em todas as esferas de governo, pelos profissionais de saúde, pelas comunidades, e organizações não governamentais.

Em decorrência dessa situação justifica-se a avaliação da implantação de ações de incentivo ao aleitamento materno no PSF, o qual atuando com uma equipe prestadora de serviços domiciliares, teria maiores oportunidades de divulgar e promover o aleitamento materno, apoiando as mães que aleitam seus filhos, melhorando a saúde e a qualidade de vida da dupla mãe/filho.

Este artigo tem como objetivo avaliar a sensibilização, os conhecimentos e capacitação das equipes de saúde da família para o desenvolvimento das ações de promoção do AM e verificar como está organizada a assistência para o desenvolvimento dessas ações em um município da região metropolitana de São Paulo.

\section{Métodos}

O presente estudo faz parte de uma pesquisa avaliativa sobre a implantação do PSF no município de Francisco Morato, São Paulo desenvolvida pelo Instituto de Saúde da Secretaria de Estado da Saúde de São Paulo, e constitui-se de uma avaliação de processo, a qual estuda as maneiras pelas quais os serviços ou intervenções são realizados e planejados para descrever o que está acontecendo. 13

Optou-se por realizar um estudo de caso, que é sempre bem delimitado por ter seus contornos claramente definidos no desenrolar do estudo, podendo ser similar a outros, mas é ao mesmo tempo distinto, pois tem um interesse próprio, singular. ${ }^{14}$

Segundo Goode e Hatt, 15 o caso se destaca por se constituir numa unidade dentro de um sistema mais amplo. $\mathrm{O}$ interesse, portanto, incide naquilo que se tem de único, de particular, mesmo que posteriormente venham a ficar evidentes certas semelhanças com outros casos ou situações. O que distingue o estudo de caso de outros tipos de estudo é a compreensão do objeto estudado como um fenômeno singular, representativo de uma realidade.

A escolha do município de Francisco Morato, se deu em decorrência da localização geográfica, do interesse do gestor municipal, da cobertura do PSF no município, e do tempo de implantação do programa. O município está a uma distância de $55 \mathrm{~km}$ a Noroeste da Grande São Paulo, com meios de transportes por rodovias e ferrovia facilitando o acesso dos pesquisadores. O gestor municipal, após conhecer os objetivos do projeto autorizou a realização da pesquisa no município, que conta com 133.728 habitantes, $96 \%$ de área urbana, com uma cobertura entre PSF e PACS de 29.468 famílias cadastradas, representando $88,65 \%$ da população. 16 O PSF foi implantado no município em 2000, contando no período da pesquisa com 10 Unidades de Saúde da Família (USF), 15 equipes e 136 profissionais, sendo 96 agentes comunitários, 15 médicos, 14 enfermeiros e 10 auxiliares de enfermagem.

Foram entrevistados membros das equipes de saúde da família selecionados através do processo de amostragem aleatória sistemática, estratificada sob o critério de proporcionalidade, uma vez que havia interesse em incluir todas as categorias de profissionais que participam do PSF no município. $17 \mathrm{O}$ número de profissionais sorteados em cada um dos estratos (médico, enfermeiro, auxiliar de enfermagem e agente comunitário), representa a proporção dos mesmos em relação ao número total dos profissionais.

O tamanho da amostra foi calculado conforme tabela "Tamanho de amostra para estimar proporções", publicada por Silva17 utilizando os seguintes parâmetros: proporção da população $80 \%$, precisão absoluta $10 \%$, nível de significância 5\%, chegando-se ao tamanho da amostra de 61 profissionais.

O instrumento de coleta de dados constituiu-se de um questionário semi-estruturado direcionado aos profissionais das equipes de saúde da família, previamente testado divido em blocos: Bloco 1 - Características dos Profissionais; Bloco 2 - Sensibilização dos Profissionais quanto ao Aleitamento Materno; Bloco 3 - Conhecimento dos Profissionais sobre Manejo do Aleitamento Materno; Bloco 4 - Capacitação dos Profissionais sobre Aleitamento Materno; Bloco 5 - Organização das Ações de Promoção, Proteção e Apoio ao Aleitamento Materno.

Após a coleta de dados, iniciou-se o trabalho de 
categorização das questões abertas. Essa categorização foi feita mediante a criação de um manual de códigos, respeitando todas as respostas de todos os profissionais envolvidos na pesquisa, sendo atribuído um conceito como forma avaliativa: satisfatório, parcialmente satisfatório, insatisfatório.

Os conceitos satisfatório, parcialmente satisfatório, e insatisfatório, atribuídos às respostas dos questionários foram fundamentados no manual sobre "Manejo e promoção do aleitamento materno"18 e nas orientações do "Curso de Aconselhamento em Amamentação".19

Para analisar a influência das variáveis: sexo, idade, tempo de atuação no PSF e função dos profissionais entrevistados sobre o conhecimento dos mesmos sobre AM, foi criado um escore, que variou de 0 a 18 pontos conforme a somatória de questões respondidas satisfatoriamente, sendo dividido em três categorias: até 9 acertos; de 9-12 acertos e de 13-18 acertos. A análise das associações foi feita utilizando-se o teste qui-quadrado, adotando-se nível de significância de $5 \%$.

A digitação e a análise dos dados coletados foram feitas utilizando-se o programa Epi-info 6 .

A pesquisa foi aprovada pelo Comitê de Ética do Instituto de Saúde, e os coordenadores das equipes de saúde de família e os entrevistados participaram da pesquisa mediante a assinatura de consentimento informado.

\section{Resultados}

As características dos 61 profissionais que participaram da pesquisa são apresentadas na Tabela 1. Verificou-se que a maioria dos profissionais era do sexo feminino (82\%), e de agente comunitários $(72,1 \%)$ e estavam distribuídos por todas as unidades do PSF do município. A idade dos entrevistados variou de 20 a 51 anos (média de 28 anos). Em relação ao tempo de atuação dos profissionais, obteve-se uma média de 18 meses (mínimo de dois e um máximo de 30 meses no PSF).

Para verificar a sensibilização dos profissionais para o trabalho com AM, foram elaboradas três questões. Na primeira, verificou-se que $45 \%$ dos entrevistados, ao serem solicitados a citar três ações prioritárias referentes à saúde da criança desenvolvidas pelo município, responderam espontaneamente ao incentivo ao aleitamento materno. Na segunda questão, verificou-se que $60(98,4 \%)$ profissionais das equipes de saúde da família reconheceram a importância do aleitamento materno para a saúde infantil, dos quais $30(49,2 \%)$, responderam satisfatoria- mente fazendo três citações sobre a importância da amamentação. As vantagens mais citadas foram relacionadas aos fatores imunológicos $(54,1 \%)$, desenvolvimento neuropsicomotor $(42,6 \%)$ e nutrição $(39,2 \%)$. Na terceira questão $60(98,4 \%)$ reconheceram que o aleitamento materno apresenta vantagens para as mães, sendo que $19(31,1 \%)$ listaram satisfatoriamente três vantagens, sendo as mais citadas: vínculo mãe-filho (44,3\%), prevenção de câncer de mama $(32,8 \%)$ e menor custo $(31,1 \%)$.

A Tabela 2 apresenta as respostas relacionadas aos conhecimentos dos profissionais sobre manejo do aleitamento materno. Verifica-se que 59 (96,7\%) reconheceram que a amamentação deve ser praticada exclusivamente até o sexto mês de vida e $58(95,1 \%)$ referiram que não existe necessidade de oferecer suplementos aos bebês (água/chá) nesse período. Porém quanto ao período de duração total do aleitamento materno apenas $15(24,6 \%)$ profissionais entrevistados orientaram a manutenção do $\mathrm{AM}$ até os dois anos de vida do bebê, conforme recomendação da Organização Mundial da Saúde (OMS). 20

Quarenta e dois profissionais $(68,9 \%)$ orientaram a amamentação sob livre demanda, sem estabelecer horários e duração para as mamadas.

Dos 61 entrevistados $59(96,7 \%)$ referiram a não necessidade do uso da chupeta e a não existência de leite fraco. Vinte e sete $(44,3 \%)$ acreditavam que não há necessidade de oferecer os dois peitos em todas as mamadas, sendo que $29(47,3 \%)$ do total da amostra referiram que existe diferença entre o leite do início da mamada para o leite do final da mamada no mesmo peito. Entre esses, porém, apenas 13 $(44,8 \%)$ souberam explicitar essas diferenças. Cinqüenta e quatro $(88,5 \%)$ informaram orientar as mães quanto ao posicionamento e pega, entre esses, porém, apenas $21(38,9 \%)$ orientam satisfatoriamente. Quarenta e dois referiram ensinar as mães a executar a ordenha ou expresão manual do leite $(68,9 \%)$, sendo que entre esses, nove $(21,4 \%)$ orientaram satisfatoriamente. Cinqüenta e sete entrevistados referem orientar as mães sobre a cólica do bebê caso necessário, porém apenas $21(36,8 \%)$ orientaram satisfatoriamente. Quanto às questões relativas à dor no mamilo e insuficiência de leite materno, $24(39,3 \%)$ entrevistados responderam que são causadas por problemas de pega. Sobre a causa do ingurgitamento mamário, $31(50,8 \%)$ responderam ser causado pelo não esvaziamento adequado das mamas. 
Verificou-se uma associação estatisticamente significativa entre função do profissional e número de questões respondidas satisfatoriamente $(p=0,029)$ sendo que a maior frequiência de acertos se concentra nas enfermeiras e auxiliares de enfermagem (Tabela 3).

A associação entre a variável sexo e o número de acertos não foi significativa $(p=0,589)$. Verificou-se que as unidades do PSF do município são bastante heterogêneas quanto à existência de profissionais que têm conhecimento sobre AM e manejo clinico da amamentação, porém a associação entre essas variáveis também não foi significativa.

Em relação à variável tempo de atuação no PSF, verificou-se maior concentração de acertos entre profissionais que trabalham entre 24 e 30 meses no programa, porém a associação entre as variáveis não foi estatisticamente significativa.

Quanto à capacitação, verificou-se que 54 $(88,5 \%)$ entrevistados referiram ter recebido algum tipo de treinamento em AM, sendo que, dentre eles, $36(66,7 \%)$ foram treinados em cursos de capacitação do PSF, tendo como tipo de treinamento seminários e palestras.

Dos profissionais que informaram ter recebido treinamento em AM, 50,9\% foram treinados no início da implantação do PSF (1999), 35,8\% receberam treinamento em 2001 e $9,4 \%$ receberam treinamento em 2002.

\section{Tabela 1}

Distribuição dos profissionais entrevistados segundo sexo, função e Unidade de Saúde da Família. Francisco Morato, São Paulo, 2002.

\begin{tabular}{|c|c|c|c|}
\hline Variável & & $N=61$ & $\%$ \\
\hline \multirow[t]{2}{*}{ Sexo } & Masculino & 11 & 18,0 \\
\hline & Feminino & 50 & 82,0 \\
\hline \multirow[t]{4}{*}{ Função } & Médico & 7 & 11,5 \\
\hline & Enfermeira & 6 & 9,8 \\
\hline & Auxiliar de Enfermagem & 4 & 6,6 \\
\hline & Agentes & 44 & 72,1 \\
\hline \multirow[t]{10}{*}{ Unidade } & Jardim Alegria & 7 & 11,5 \\
\hline & Lions & 7 & 11,5 \\
\hline & Jardim Rosas & 7 & 11,5 \\
\hline & Jardim Arpoador & 4 & 6,6 \\
\hline & Parque 120 & 9 & 14,8 \\
\hline & Centro & 5 & 8,2 \\
\hline & Santo Antônio & 3 & 4,9 \\
\hline & Água Vermelha & 7 & 11,5 \\
\hline & Casa Grande & 4 & 6,6 \\
\hline & Vassouras & 8 & 13,1 \\
\hline
\end{tabular}


Tabela 2

Conhecimento dos profissionais entrevistados sobre aconselhamento e manejo do aleitamento materno. Francisco Morato, São Paulo, 2002.

\begin{tabular}{|c|c|c|c|c|c|c|c|c|}
\hline \multirow{3}{*}{ Questão } & \multicolumn{8}{|c|}{ Respostas } \\
\hline & \multicolumn{2}{|c|}{ Satisfatório } & \multicolumn{2}{|c|}{ Parcialmente } & \multicolumn{2}{|c|}{ Insatisfatório } & \multicolumn{2}{|c|}{ Total } \\
\hline & $\mathrm{n}$ & $\%$ & $\mathrm{n}$ & $\%$ & $\mathrm{n}$ & $\%$ & $\mathrm{n}$ & $\%$ \\
\hline $\begin{array}{l}\text { Como deve ser a alimentação da criança até seis meses de } \\
\text { vida? }\end{array}$ & 59 & 96,7 & - & - & 2 & 3,3 & 61 & 100,0 \\
\hline $\begin{array}{l}\text { Existe necessidade de oferecer água ou chá para bebês até } \\
\text { seis meses de vida? }\end{array}$ & 58 & 95,1 & - & - & 3 & 4,9 & 61 & 100,0 \\
\hline Até quando as mães devem amamentar seus bebês? & 15 & 24,6 & 2 & 3,3 & 44 & 72,1 & 61 & 100,0 \\
\hline $\begin{array}{l}\text { Como as mães são orientadas sobre os horários e a duração } \\
\text { das mamadas? }\end{array}$ & 42 & 68,9 & 1 & 1,6 & 18 & 29,5 & 61 & 100,0 \\
\hline $\begin{array}{l}\text { Você acredita que possa ser necessário o uso da chupeta } \\
\text { nos intervalos das mamadas? }\end{array}$ & 59 & 96,7 & - & - & 2 & 3,3 & 61 & 100,0 \\
\hline Na sua opinião existe leite fraco? & 59 & 96,7 & - & - & 2 & 3,3 & 61 & 100,0 \\
\hline $\begin{array}{l}\text { É necessário que a mãe ofereça em toda mamada os dois } \\
\text { peitos? }\end{array}$ & 27 & 4,3 & - & - & 34 & 55,7 & 61 & 100,0 \\
\hline $\begin{array}{l}\text { Existe diferença entre o leite do início da mamada para o } \\
\text { leite do final da mamada? }\end{array}$ & 29 & 47,5 & - & - & 32 & 52,5 & 61 & 100,0 \\
\hline Se sim, qual? & 13 & 45,0 & 2 & 6,8 & 14 & 48,3 & 29 & 100,0 \\
\hline $\begin{array}{l}\text { Você demonstra ou ensina às mães como fazer com seus } \\
\text { bebês quanto ao posicionamento e pega para uma boa uma } \\
\text { boa amamentação? }\end{array}$ & 54 & 88,5 & - & - & 7 & 11,5 & 61 & 100,0 \\
\hline Se sim, como? & 21 & 38,9 & 26 & 48,1 & 7 & 13,0 & 54 & 100,0 \\
\hline $\begin{array}{l}\text { Você demonstra ou ensina as mães como fazer a expressão } \\
\text { manual do leite ou ordenha do leite }\end{array}$ & 42 & 68,9 & - & - & 19 & 31,1 & 61 & 100,0 \\
\hline Se sim, como orienta? & 9 & 21,4 & 3 & 31,0 & 20 & 47,6 & 42 & 100,0 \\
\hline Você orienta a mãe sobre a cólica do bebê? & 57 & 93,4 & - & - & 4 & 6,6 & 61 & 100,0 \\
\hline Como? & 21 & 36,8 & 33 & 57,9 & 3 & 5,3 & 57 & 100,0 \\
\hline Qual a principal causa de dor no mamilo? & 24 & 39,3 & 7 & 11,5 & 30 & 49,2 & 61 & 100,0 \\
\hline $\begin{array}{l}\text { Qual a causa mais comum para insuficiência de leite } \\
\text { materno? }\end{array}$ & 24 & 39,3 & 20 & 32,8 & 17 & 27,9 & 61 & 100,0 \\
\hline Qual a causa mais comum para o ingurgitamento mamário? & 31 & 50,8 & 15 & 24,6 & 15 & 24,6 & 61 & 100,0 \\
\hline
\end{tabular}


Distribuição dos profissionais segundo a função e total de acertos nas questões referentes ao manejo clinico em aleitamento materno. Francisco Morato, São Paulo, 2002.

\begin{tabular}{|c|c|c|c|c|c|}
\hline Função & Até 9 & de $9-12$ & de $13-18$ & Total & Valor de $p$ \\
\hline Médico & 2 & 3 & 2 & 7 & \\
\hline Enfermeiro & 0 & 1 & 5 & 6 & \\
\hline Auxiliar de Enfermagem & 1 & 1 & 2 & 4 & 0,029 \\
\hline Agente Comunitário & 17 & 20 & 7 & 44 & \\
\hline Total & 20 & 25 & 16 & 61 & \\
\hline
\end{tabular}

Em relação à carga horária, foram considerados 44 profissionais, uma vez que referiram a carga horária total de cursos de especialização que concluíram e não especificamente horas de treinamento em AM, e outros responderam que não se lembravam da carga horária do curso. Verificou-se para esses profissionais uma média de nove horas e 36 minutos em treinamento sobre aleitamento materno, oferecido pelo PSF do município.

Quanto à organização das ações de promoção e apoio ao AM, $45(73,8 \%)$ entrevistados referiram que a orientação sobre AM é feita no pré-natal e no pós-parto, pelo médico, pela enfermeira e pelo agente comunitário, sendo que $16(16,2 \%)$ citaram que a orientação é feita pelo enfermeiro nas consultas de puericultura e/ou nas visitas domiciliares pelos agentes comunitários. Sobre a existência de grupos de apoio nas USF do município estudado, 21 $(34,4 \%)$ mencionaram a existência dos grupos em suas USF dos quais $15(71,4 \%)$ relataram que as mães são sempre encaminhadas para os grupos.

Dez causas foram citadas para o desmame precoce, sendo as mais freqüentes: o mito do leite fraco $(32,8 \%)$, o desconforto da mama dolorida $(29,5 \%)$, a volta ao trabalho pelas mulheres que estão inseridas no mercado de trabalho $(24,6 \%)$ e a falta de confiança da mãe quanto à adequação do leite materno como alimento ideal para seu filho (24,6\%).

As sugestões mais citadas para melhor desenvolvimento do trabalho de incentivo à amamentação foram: necessidade de ações de educação em saúde $(36,1 \%)$, necessidade de material educativo e espaço físico adequado para o atendimento $(34,4 \%)$, campanhas de promoção sobre AM nos meios de comunicação $(29,5 \%)$ e necessidade de treinamentos periódicos sobre AM principalmente aos agentes comunitários (23\%).

\section{Discussão}

A atenção à criança é uma das prioridades do PSF e o incentivo ao aleitamento materno constitui-se em uma de suas ações prioritárias. No entanto não foram encontrados estudos que avaliem especificamente a capacitação de Equipes de Saúde da Família (ESF) em AM, o que em parte prejudicará a discussão dos achados deste trabalho.

Estudos que avaliam a capacitação de profissionais de saúde em AM (não inseridos no PSF) apontam resultados semelhantes aos encontrados nesse trabalho.

Uma pesquisa realizada em São Paulo e Recife identificou que os profissionais de saúde conheciam melhor a teoria do que a prática sobre aleitamento materno.21

Panigassi, 22 analisando uma amostra de 58 pediatras, cinco enfermeiros, 24 auxiliares e quatro atendentes prestadores de serviços das UBS da cidade de Campinas, SP e região concluiu que as orientações oferecidas pelos profissionais de saúde, de certa forma refletem aquelas recebidas durante o período de graduação e residência médica, consideradas insuficientes em seu trabalho.

Os profissionais entrevistados no município estudado, no presente trabalho, também estão sensibilizados e reconhecem a importância do aleitamento materno para a saúde tanto do bebê quanto da mãe e procuram informar as mães das áreas adstritas sobre as vantagens do aleitamento materno. Entretanto, faltam conhecimentos sobre o manejo clínico da amamentação para dar melhor orientação e apoio às mães. Esse fato pôde ser observado quando foram avaliados os conhecimentos sobre o manejo clínico do aleitamento materno. Nas questões relativas à pega e posicionamento, ordenha manual e cólicas do bebê, entre outras, o percentual de profissionais que 
fazem alguma orientação é elevada, porém, quando se pergunta como é feita a orientação, o proporção de respostas satisfatórias é pequena.

Segundo a OMS, 20 para que o início e o estabelecimento do aleitamento tenham êxito, as mães necessitam do apoio ativo, durante a gravidez e após o parto, não apenas de suas famílias e comunidades, mas também de todo o sistema de saúde. Idealmente, todos os profissionais de saúde com quem gestantes e puérperas entrassem em contato deveriam estar comprometidos com a promoção do aleitamento materno, e ser capazes de fornecer informações apropriadas, assim como de demonstrar habilidade prática no manejo do aleitamento.

A pesquisa realizada no município de Francisco Morato aponta uma realidade bastante diferente do que é proposto. Os profissionais das ESF não estão capacitados de maneira uniforme, uma vez que foi detectada diferença estatisticamente significativa na associação entre os conhecimentos em AM e a função exercida na equipe. Chama atenção o fato de que os profissionais mais capacitados são os da área de enfermagem. O profissional médico do PSF parece estar mais voltado à prática assistencial curativa, sendo que o AM, que é uma ação de promoção à saúde da criança, necessitaria de maior atenção. Freqüentemente a formação desses profissionais de saúde é mais voltada para a mamadeira, "uma tecnologia moderna" que pode ser ensinada e supervisionada, do que para preparar as mães com vistas a um bom aleitamento. Esse fato é preocupante, uma vez que o saber médico exerce grande influência sobre a sua população e sobre os agentes comunitários, que são o elo principal de ligação entre a USF e a comunidade e que, portanto, deveriam ser treinados como agentes multiplicadores do AM.

Tognetti 23 considera que os programas comunitários são um meio efetivo de prevenir o declínio da amamentação. Segundo Garcia 24 os recursos humanos da própria comunidade favorecem a continuidade dos programas, dado que se propicia uma atuação dos participantes nas decisões e nas atividades, levando em conta o contexto cultural e as necessidades da comunidade. Além disso, a participação de pessoas da comunidade leva a uma difusão mais eficiente dos conhecimentos, e por outro lado, provoca uma organização e uma responsabilidade no sentido de valorizar práticas que melhorem a saúde das crianças. Como exemplo disso o autor menciona, em seu livro, o impacto causado pelos agentes comunitários do Programa de Saúde da Família nos municípios de Olinda, Pernambuco e de Quixadá e Icapuí no Ceará.

Em relação à capacitação de profissionais do
PSF em AM, não existe até o momento uma proposta definida. A OMS e o Fundo das Nações Unidas para a Infância (UNICEF) propõem atualmente três cursos de capacitação em aleitamento materno para pessoal que lida diretamente com assistência a saúde: "Manejo Clinico e Promoção do Aleitamento Materno em um Hospital Amigo da Criança", um curso de 18 horas, com três horas de prática clínica; "Guia para Treinamento em Manejo do Aleitamento Materno"; com duração de 80 horas, com seis horas de prática clínica e curso de "Aconselhamento em Amamentação", com duração de 40 horas com oito horas de prática clínica. 25

Os profissionais entrevistados na pesquisa não receberam tais cursos, sendo que a capacitação por eles citada estava aquém do recomendado pela OMS e o UNICEF, especialmente em relação à carga horária. Sabe-se que um curso de capacitação em AM deve ter no mínimo 18 horas, e a média de treinamento dos profissionais do PSF de Francisco Morato está em torno de nove horas, portanto, $48 \%$ abaixo do recomendado. Verificou-se também que o tempo de atuação no PSF não mostrou influência significativa sobre os conhecimentos em AM, o que sugere que somente a prática das equipes não é suficiente para a capacitação nesse tema, sendo necessário definir uma proposta formal para o treinamento desses profissionais.

O profissional capacitado em aleitamento materno poderia estar trabalhando junto à população não somente prestando assistência, mas também na promoção e educação em saúde da sua comunidade, sendo que este é o papel principal do Programa de Saúde da Família para prevenir agravos. As mães precisam ser acompanhadas e educadas em relação ao aleitamento materno porque o ato de amamentar, embora pareça natural do ser, está envolvido em crenças, mitos, culturas e experiências concretas que envolvem as mulheres, mães e nutrizes.

As mães que têm acesso à informação através dos meios de comunicações sobre o aleitamento materno, dependendo do grau de compreensão, passam a conhecer bem sua importância, mas se não tiverem um acompanhamento e o apoio dos profissionais de saúde e da família normalmente não conseguem superar as dificuldades, ocorrendo o desmame precoce, que põe em risco a saúde do bebê.

A World Health Organization (WHO) 25 estima que atualmente o AM salva a vida de seis milhões de crianças a cada ano, prevenindo diarréia e infecções respiratórias agudas e é responsável por um quarto a um terço da diminuição da fertilidade observada nas últimas décadas.

No caso específico de Francisco Morato a inten- 
sificação da promoção do AM seria de grande benefício, pois esse município apresenta baixa prevalência de aleitamento materno e coeficientes de mortalidade infantil que superam a média do Estado de São Paulo. 26

Escuder et al.,27 analisando os coeficientes de mortalidade infantil e a prevalência da amamentação em municípios da região metropolitana de São Paulo, concluíram que a mortalidade infantil no município de Francisco Morato sofreria redução substancial com o aumento da freqüência da amamentação, especialmente em seu componente pósneonatal.
Uma pesquisa realizada durante a campanha de vacina em 2000 mostrou uma prevalência de amamentação exclusiva de apenas $16 \%$ em menores de quatro meses 27 indicando a necessidade de intensificação de ações pró-amamentação.

Os próprios profissionais do PSF envolvidos na pesquisa apontam sugestões relevantes, incluindo a necessidade de treinamentos em AM. Acredita-se que um maior investimento na capacitação das ESF em AM poderia levar ao melhor aproveitamento do potencial do PSF para a promoção do AM nas comunidades em que é implantado.

\section{Referências}

1. Brasil. Constituição (1988). Da Saúde. Art.196. Título VIII. Cap. II. Seção II. 24. ed. Brasília (DF): Casa Civil, 2001.

2. Brasil. Leis, Decretos, etc. Lei no. 8080 de 19 de setembro de 1990. Dispõe sobre as condições para a promoção, proteção e recuperação da saúde, a organização e o funcionamento dos serviços correspondentes e dá outras providências. Diário Oficial da União [DOU] Brasília (DF) 20 setembro 1990; 18055.

3. Costa Neto MM. O currículo médico e o sistema de saúde em construção. Rev Bras Saúde Fam 2000; 2: 46-51.

4. Ministério da Saúde. Secretaria de Políticas de Saúde. Departamento de Atenção Básica. A implantação da Unidade Básica de Saúde da Família. Brasília (DF): O Ministério; 2000

5. Bonfim LA, Bastos ACS. O impacto sociocultural do Programa Saúde da Família (PSF): uma proposta de avaliação. Cad Saúde Pública 1998; 14: 429-35.

6. Victora CG, Vaughan JP, Lombardi C, Fuchs SMC, Gigante LP, Nobre LC, Teixeira MB, Moreira LB, Barros FC. Evidence for protection by breast feefing against infant deaths from infectiuos diseases in Brazil. Lancet 1987; 2: 19-22.

7. Monteiro CA, Rea MF, Victora CG. Can infant mortality be reduced by promoting breast feeding? Evidence from São Paulo city. Health Policy Plan 1990; 5: 23-9.

8. Woolridge MW, Phil D, Baum JD. Recent advances in breast feeding. Acta Paediatr JPN 1993; 35: 1-12.

9. Venancio SI, Monteiro CA. A tendência da prática da amamentação no Brasil nas décadas de 70 e 80 . Rev Bras Epidemiol 1998; 1: 40-39.

10. BEMFAM (Sociedade Civil Bem-Estar da Família no Brasil). Pesquisa Nacional sobre Demografia e Saúde: relatório. Rio de Janeiro: UNICEF; 1997

11. Ministério da Saúde. Secretaria de Políticas de Saúde. Área da Saúde da Criança. Prevalência de aleitamento materno nas capitais brasileiras e no Distrito Federal. Brasília (DF): O Ministério; 2001.

12. WHO (Word Health Organization). Innocenti Declaration on the protection, promotion and support of breast-feeding. Ecol Food Nutr 1991; 26: 271-3.

13. ABIA (Associação Brasileira Interdisciplinar de AIDS). Avaliação em HIV/AIDS: uma perspectiva internacional. Rio de Janeiro: A Associação; 2001. (Fundamentos de avaliação, 2).

14. Lüdke M, Meda A. Pesquisa em educação: abordagens qualitativas. São Paulo: EPU; 1986.

15. Goode MJ, Hatt K. Métodos em pesquisa social. São Paulo: Nacional;1968.

16 IBGE (Instituto Brasileiro de Geografia e Estatística). Cidades. Disponível em: Http://www.ibge.gov.br/cidades sat/defaultsant/php. [15 mar 2002]

17. Silva NN. Amostragem probabilística. São Paulo: EDUSP; 1998.

18. UNICEF (Fundo das Nações Unidas para a Infância), Ministério da Saúde. Manejo e promoção do aleitamento materno: Programa Nacional de Incentivo ao Aleitamento Materno. Brasília (DF): O Ministério; 1993.

19. OMS (Organização Mundial da Saúde), UNICEF (Fundo das Nações Unidas para a Infância). Aconselhamento em aleitamento materno: manual do participante. Fortaleza: Universidade Federal do Ceará; 1997.

20. OMS (Organização Mundial da Saúde), UNICEF (Fundo das Nações Unidas para a Infância). Proteção, promoção e apoio ao aleitamento materno: o papel especial dos serviços materno-infantis. Genebra: 1989.

21. Rea MF, Berquó ES. Impact of the Brazilian national breast feeding programme on mothers in greater São Paulo. Bull World Health Organ 1990; 68: 365-71

22. Panigassi G. Profissionais de saúde: conhecimento e conduta em aleitamento materno [dissertação mestrado]. Campinas: Faculdade de Ciências Médicas da Universidade Estadual de Campinas; 2000.

23. Tognetti J. Evaluating breast feeding promotion programmes. In: Jelliffe DB, Jelliffe EF, editors. Programmes to promote breast feeding. New York: Oxford University Press; 1988; p. 405-9. 
24. Garcia MV. Formação de agentes comunitários para a promoção do aleitamento materno e da estimulação do bebê. São Paulo: Manole; 2002.

25. WHO (World Health Organization). Breast feeding: the technical basis and recomendations for action. Geneva: The Organization; 1993

Recebido em 16 de março de 2004

Versão final reapresentada em 5 de maio de 2004

Aprovado em 8 de maio de 2004
26. São Paulo (Estado). Secretaria de Saúde. Atualização dos dados de mortalidade infantil. Disponível em: http://www.saude.sp.gov.br/html/fr_dados.htm. [15 mar 2002].

27. Escuder MML, Venancio SI, Pereira JCR. Estimativa de impacto da amamentação sobre a mortalidade infantil. Rev Saúde Publica 2003; 37: 319-25. 